REVISTA ANDALUZA DE ANTROPOLOGÍA.

NÚMERO 5: APORTACIONES Y POTENCIALIDADES DE LA ANTROPOLOGÍA DE LA SALUD.

SEPTIEMBRE DE 2013

ISSN 2174-6796

[pp. 105-130]

http://dx.doi.org/10.12795/RAA.2013.i05.06

Fecha de Recepción: 30-04-2013

Fecha de Aceptación: 19-06-2013

\title{
EL SISTEMA ANDINO DE SALUD (SAS) EN EL ESTADO PLURINACIONAL DEL ECUADOR
}

José Yánez del Pozo

Centro de Pensamiento y Culturas Andinas TINKUNAKUY

\section{Andrea Yánez \\ Hospital Raúl Maldonado Mejía}

\section{Resumen.}

El presente artículo intenta una aproximación a la situación de la salud en el Ecuador, en el antiguo territorio del Pueblo Kayampi, ubicado al norte del país y uno de los 14 pueblos de la nacionalidad kichwa, reconocida oficialmente. Tras una descripción general de las condiciones socio-económicas de la zona, nos acercarnos a la historia y a la problemática de salud del Pueblo Kayambi, dentro de la cual analizamos brevemente los fundamentos del Sistema Andino de Salud (SAS) para entender mejor la sabiduría y la actividad de las parteras $^{1}$, dentro de lo que nos parece es la vida diaria de la gente. Cuando se producen las urgencias y las emergencias, evidentemente que hay que acudir al hospital, por lo que creemos de interés, tener una idea general del personal especializado del Sistema Occidental de Salud (SOS), que primero se forma en una institución académica y que luego trabaja en un hospital. Para comprender mejor todo esto, hacemos un punteo de la actividad académica de una estudiante de medicina de una facultad especifica de

1. Varias de las ideas que aparecen en este artículo han sido tomadas de una investigación realizada por el autor sobre las parteras del Pueblo Kayambi (en prensa). En la elaboración de este artículo ha colaborado Andrea Yánez del Pozo. 
Quito, incluyendo la materia denominada Antropología Médica, para luego dar algunos datos generales de las actividades de algunos profesionales en el Hospital Público Raúl Maldonado Mejía del cantón ${ }^{2}$. Para concluir, dejamos sentada la posibilidad de que, con el tiempo, se pueda discutir en el país la relación que pudiera haber entre los dos sistemas que sería, a nuestro entender, lo único que podría mantener la vida de nuestros pueblos, en las actuales circunstancias.

Palabras clave: nacionalidad kichwa, Pueblo Kayambi, Sistema Andino de Salud, Sistema Occidental de Salud, Antropología Médica, Sistema Complementario de Salud.

\begin{abstract}
.
This article makes an approach to health situation in Ecuador, taking as a case study the territory of Kayambi people, part of the Kichwa nationality, officially recognized. After a general approach to the socio-economic conditions of the zone, we get a glance of history of this people to understand better the foundations of Andean Health System, and especially the midwifes wisdom and activities, as a part of their daily lives. If an urgency of an emergency takes place, obviously people should go a hospital. For that reason we consider important also to take a look to the process of the Western Health System (WHS), forming its personnel in a school of Quito, including something about the class called Medical Anthropology, before giving some information about a public hospital close to Quito, where some of these professionals work later on. To conclude the paper, we end with the question of how possible it could be having a better relation between the two systems as the only way to solve the health problems of our peoples.
\end{abstract}

Key words: Kichwa nationality, Kayambi People, Andean health System, Western Health System, Medical Anthropology, Complementary Health System

\title{
1. ANTECEDENTES
}

Bajo el modelo agroexportador, el Ecuador ha visto cómo la mayor parte de la tierra cultivable se ha concentrado en pocas manos, de qué manera se han dedicado las mejores tierras al cultivo de productos para la exportación y, por fin, cómo la Madre Tierra, la Pachamama, ha sido destruida lenta pero inconteniblemente. En el caso concreto de las tierras del Pueblo Kayambi esto se ha dado a lo largo de la historia. Como se puede entender por los estudios realizados, (Prieto, 1978; Yánez, 1986; Ramón, 1987, entre otros), las haciendas han sido la principal forma de posesión en las zona de Pesillo, Zuleta y todo el territorio de Pueblo Kayambi. Y ya desde hace dos décadas, más o menos, las

2. Aporte de Andrea Yánez, médica residente en el Hospital Raúl Maldonado Mejía de Cayambe. 
empresas productoras de flores han acaparado, además, las mejores tierras con todo lo que eso ha supuesto para la salud de la población. A causa de la mala situación del campo del Pueblo Kayambi cada vez más gente deja la agricultura para dedicarse al trabajo en las empresas florícolas de la zona, con todos los perjuicios ambientales y humanos, tal como se señala en el estudio de Breilh y Tillería.

"La floricultura permite ejemplificar el caso de una rama agroindustrial de alta tecnología productiva que no se corresponde a un beneficio social equitativo ni a los cuidados hacia el ser humano y el ambiente que se esperaría atienda un sector tan informado y rentable" (Breilh y Tillería, 2009: 171).

El estudio al que hacemos referencia es muy explícito en señalar los fundamentales perjuicios que las florícolas producen a la tierra y al territorio kayambi y su gente. Los impactos en los ecosistemas, el uso intensivo del agua y la diseminación de los tóxicos son los mayores problemas para la salud de los kayambis. El uso del agua es tan grande que una plantación de flores en la zona de Cayambe, por ejemplo, usa 60 veces más agua por hectárea/mes que el de una hacienda tradicional, 1000 veces más que una pequeña propiedad campesina y hasta 1,07 veces más que el agua que se consume por mes en una hectárea de Quito Metropolitano con su gente e industrias incluidas (Breilh y Tillería, 2009: 173).

La pérdida de la biomasa, la contaminación de los ríos y sus cauces así como la contaminación de la cadena alimentaria afecta directamente a los campesinos de comunidades como la de Cananvalle en Tabacundo (Breilh y Tillería, 2009: 175). Si a esto se juntan los acelerados cambios en los modos de vida de campesinos y agricultores, el estrés producido por las demandas laborales, la exposición que tiene la gente trabajadora, especialmente las mujeres, a los químicos que se usan y que producen intoxicación la lista de daños a está completa.

"De modo general los ritmos de producción de flores cortadas son intensos y no permiten un mínimo control del trabajador sobre el proceso productivo. Las jornadas de trabajo son extenuantes y estresantes por su alta exigencia, sin pausas compensatorias ni ejercicios físicos de distensión. Los tiempos para el descanso diario y periódico son mínimos e insuficientes. Las tareas, según sus tipos, imponen procesos diversos dañinos: sobrecarga física dinámica, combinada en algunas secciones con sobrecarga estática (como en pos cosecha); movimientos repetitivos; fluctuaciones térmicas; exposición al ruido, a irritantes respiratorios y dérmicos; infecciones de hongos en la piel, y sobre todo exposición a agroquímicos -eventualmente aguda y generalmente crónica y de baja intensidad-, por el uso indebido de sustancias de peligrosidad alta (productos de franja roja y amarilla), ocasionado por la falta de manejo alternativo e integral de plagas, la debilidad o ausencia de mecanismos de protección (deficiencias de equipo, implementación incorrecta de turnos y modos de fumigación)" (Breilh y Tillería, 2009: 179-180). 
Si el problema es grave para todos es más grave para las mujeres por sus características físicas y de reproducción biológica y cultural.

"La nueva ruralidad ha provocado especiales sobrecargas y problemas a las mujeres, no solo por lo que se ha llamado la feminización de la pobreza sino porque, con la transformación de la mujer campesina en obrera, las viejas relaciones de dependencia patriarcal tienden a reemplazarse con las relaciones de subsunción al trabajo industrial y los impactos del desgarramiento de la cultura comunitaria" (Breilh y Tillería, 2009: 180).

Según datos del Sistema Integrado de Indicadores Sociales del Ecuador (SIISE), el cantón Cayambe, ocupaba el décimo primer lugar entre los cantones del país con los índices de vulnerabilidad social más altos. Dato paradójico, pues es uno de los cantones donde existe mayor inversión económica en el país debido a la actividad florícola. Así mismo la incidencia de la pobreza de consumo alcanza el 79\% de la población y el 13,5\% de la población total del cantón recibe el bono de ayuda del Estado. Según datos del SIISE, el 79\% de la población es pobre, es decir, que estas personas pertenecen a hogares cuyo consumo per cápita, en un período determinado es inferior al valor de la canasta básica de bienes y servicios por período de tiempo (generalmente quincena o mes); y el 17,8\% son indigentes o en extrema pobreza, es decir, aquellas personas cuya canasta de alimento no satisfacen los requerimientos nutricionales de un hogar. Pese al auge de la floricultura que en los últimos diez años ha realizado grandes inversiones y ha generado el mayor número de fuentes de trabajo, Cayambe sigue siendo el cantón de Pichincha con mayor incidencia en los indicadores de pobreza presentando, por otra parte, la mayor brecha entre ricos y pobres de la provincia (Fuente Casa Campesina de Cayambe, 2002).

El otro dato importante y directamente relacionado con el tema del presente estudio es el que tiene que ver con la tasa de natalidad (y mortalidad materno- infantil) y el tipo de profesionales que atienden el parto, aunque la información no se haya recogido teniendo en cuenta la variable de pertenencia étnica. Según las estadísticas locales, durante el año 2002 nacieron 1.348 niños y fallecieron 424 personas, que representa una tasa de natalidad del 19 por 1000 habitantes y 6 defunciones por 1.000 habitantes. Situación que comparada con las tasas a nivel provincial y nacional registra niveles más altos, en especial la mortalidad infantil, que en la parroquia de Cangahua es de 117 defunciones en menores de un año por 1000 nacidos vivos (26 defunciones de 223 nacimientos). De los nacimientos registrados entre enero y diciembre del año 2002 en el Cantón Cayambe, el $61 \%$ fueron partos asistidos por profesionales de salud en las unidades de salud del Ministerio de Salud Pública. El resto fue atendido por parteras y familiares, que es lo más común en las zonas de población dispersa y rural. Entre las principales causas se mencionan también: la falta de profesionales médicos, horarios inadecuados e idiosincrasia de la gente; en zonas donde existe un alto porcentaje de población indígena, la mayor parte de los partos son asistidos por las parteras o familiares. 
Creemos que el problema seguirá empeorando, en esta zona y en las demás, mientras no haya una verdadera reforma agraria que no solamente retribuya la tierra a los propios pueblos sino que priorice la producción para el consumo y la alimentación, empiece a dar más importancia a la producción agroecológica y asociativa que no atente contra la Madre Naturaleza sino que la cuide y proteja, favorezca mecanismos de soberanía alimentaria con principios de dignidad y solidaridad al estilo de nuestros antepasados. Para conseguir estos objetivos por supuesto que se necesitaría emprender la tarea de la construcción de un nuevo modelo de vida social, basado en los principios de vida andinos que por fin reconozca que más de $65 \%$ de los alimentos sale de los pequeños productores los cuales, a su vez, son los guardianes de la yakumama, la Madre Agua que desciende de los páramos y que está en grave peligro de ser privatizada a pesar de todas las declaraciones constitucionales ${ }^{3}$.

\section{EL PUEBLO KAYAMBI. BREVE PROCESO HISTÓRICO}

La actual etapa política del Ecuador, llamada "Revolución Ciudadana", dirigida por el Presidente Rafael Correa, empezó su proceso en 2006, en medio de la expectativa general que consideraba que nuestros pueblos estaban maduros para trasformaciones profundas. Es así que una de sus primeras acciones fue la de convocar a la conformación de una Asamblea Constituyente que escribiera una nueva Constitución. Esta idea, ya planteada por los pueblos indígenas organizados, no pudo ser liderada por éstos precisamente por la concepción de ciudadanía que el nuevo gobierno empezaba a impulsar. Según algunas investigaciones últimas (Kimlicka, 2002; Yánez 2006), la idea de que la ciudadanía corresponde a las relaciones entre el individuo y el estado no ha incluido a los pueblos indígenas por el motivo de que solamente han estado en juego los llamados derechos individuales. Para pueblos en los cuales los derechos colectivos son tan importantes no bastan transformaciones que no los tomen en cuenta como tales, como pueblos milenarios que han tenido un estilo de vida comunitario. Por este mismo motivo, fue tan difícil para la Asamblea Constituyente del Ecuador aceptar la realidad de la plurinacionalidad en el Estado. Si por fin acabó siendo incluida en la redacción final fue solamente por la inmensa presión nacional e internacional y por la posibilidad de que si no se llegaba a un acuerdo, las fricciones entre gobierno y la Confederación de Nacionalidades Indígenas del Ecuador (CONAIE) serían mucho peores que las que

\footnotetext{
3. Según la Constitución, el agua tiene derechos y no puede ser privatizada. Para una comprensión mejor sobre este tema en los momentos actuales y para entender la tensión entre el gobierno ecuatoriano y las organizaciones sociales puede consultarse el Manifiesto por el agua y la vida de la Ecuarunari y demás organizaciones, 2009. Consorcio de Sistemas Comunitarios de Agua Potable - Ecuarunari - Foro Nacional de Recursos Hídricos - Observatorio Ciudadano de Servicios Públicos - Red de Ecologistas Populares, y otros, 6 de abril de 2009.
} 
actualmente se viven. De todas maneras, consideramos un avance mucho de lo escrito en la Asamblea Nacional Constituyente de Montecristi ${ }^{4}$, reunida para elaborar una nueva constitución. Aparte de declarar que la Naturaleza tiene derechos y de que el Buen Vivir (Sumak Kawsay) sería el contexto sociopolítico para el desarrollo nacional, la declaración del estado como plurinacional es, sin duda, algo sin precedentes. Con respecto a esto último, la constitución ecuatoriana de 2008 dice textualmente:

"El Ecuador es un Estado constitucional, de derechos y justicia social, democrático, soberano, independiente, unitario, intercultural, plurinacional y laico" (Art.1).

Como ya hemos dicho, para llegar a esta declaración la disputa fue ardua. No solamente porque ni el mismo presidente estaba convencido de que esto era necesario. Tampoco las dos tendencias más fuertes y, de alguna forma ligadas a los movimientos indígenas, se podían poner de acuerdo si lo más importante era la interculturalidad o la plurinacionalidad ${ }^{5}$. Sin acabar de aceptar que no puede haber relaciones interculturales verdaderas si no se ha empezado siquiera con la tarea de construir el estado plurinacional, la Constitución acabó con la declaración que ahora tenemos. Es por eso que el trabajo nuestro se inscribe plenamente en la tarea de ayudar a que los pueblos y las naciones del

4. Montecristi es un poblado de la Provincia de Manabí, en la costa ecuatoriana, y lugar de origen del general Eloy Alfaro, líder la revolución liberal de 1895, tomado por el gobierno de Correa como referente central en sus propuestas políticas.

5. PLURINACIONALIDAD. Consideramos que la plurinacionalidad en casi todos los países de América Latina no es más que el reconocimiento de una forma de organizar la sociedad que por historia nos pertenece. Al interior de los actuales estados existimos varias naciones con nuestros propios territorios y sistemas de vida. Durante la época colonial y republicana los estados han tratado de invisibilizar la existencia de otras naciones con sus pueblos vivos y sus manifestaciones políticas, económicas, sociales, culturales y espirituales propias. Para contrarrestar esta invisibilización, que es la causa de las grandes desigualdades en las condiciones de vida y estado de salud de nuestra gente, algunas de las naciones y muchos de sus pueblos hemos asumido el reto de reconstituirnos como tales en torno a nuestros propios territorios, sistemas de producción, educación y salud, sistemas de administración de justicia y sistemas de vivencia de nuestras propias espiritualidades

INTERCULTURALIDAD. Solamente cuando las sociedades modernas empiecen a entender y aceptar que hay naciones y pueblos que piensan y viven según lógicas de pensamiento diferentes podremos decir que es posible otro sistema de vida en el que haya la oportunidad de practicar una verdadera interculturalidad. Creer que la interculturalidad debe ser practicada solamente por los llamados pueblos indígenas es insuficiente. Debemos avanzar hacia la reconstitución de las naciones y pueblos originarios con sus propios sistemas y estilos de vida, dentro de estados plurinacionales como la base sobre la cual se pueda vivir una real interculturalidad y una verdadera armonización de estrategias de salud comunitarias e institucionales a partir de los principios profundos del sistema de conocimiento indígena. 
Ecuador empiecen a autoreconocerse y a reconocerse, a partir de su propia memoria colectiva, como lo que verdaderamente son $^{6}$. En el caso de nuestra zona de estudio, el pueblo Kayampi remonta sus orígenes a los tiempos preincaicos. La zona está llena de pucarás o fortalezas así como de sitios sagrados, recientemente recuperados como es el caso del sitio actualmente llamado PUNTZIAZIL al cual volveremos después al hablar de la religiosidad y la fiesta. Sin embargo, tal vez el sitio más representativo de la importancia de Pueblo Kayambi en épocas antiguas sea el complejo de COCHASQUÍ, con 1500 años de antigüedad.

En cada una de las épocas que le ha tocado vivir a este pueblo siempre se ha hecho presente una sabia lógica de resistencia que ha hecho posible su supervivencia hasta los tiempos actuales. Desde tiempos inmemoriales, este pueblo ha hecho uso de los diversos pisos ecológicos de su variada geografía. En unidad con el Pueblo de los Otavalos y el Pueblo de los Karankis ${ }^{7}$, el pueblo Kayambi opuso una resistencia tenaz a la presencia incaica liderada por Nasacota Puento lo que le valió inclusive una gran masacre en Yawarkucha (Oberem, 1981). Cuando ocurrió la invasión europea, según Ramón (1987) los Kayampis inteligentemente desarrollaron una estrategia llamada de pacto asimétrico, según la cual si bien los europeos tenían el control de la tierra, la economía y la política, los habitantes originarios no se dejaron dominar totalmente al mantener varias de sus estructuras propias, entre las cuales destacan las siguientes: el mantenimiento de un territorio étnico distinto del español, las relaciones de parentesco al interior del trabajo hacendatario, el mantenimiento de algunas instituciones como los mindalaes, a través de las cofradías, como una forma sincrética (sic) de resistir y, por último, la rebelión misma como la ocurrida entre 1666 y 1667 (Ramón, 1987:134-136).

La república organizó el territorio con la invisibilización total de los pueblos indígenas. Se ideó la administración del nuevo estado bajo criterios foráneos con la división en provincias, cantones, parroquias y comunidades o barrios. Pueblos enteros fueron segmentados y obligados a vivir de espaldas a sus propios hermanos. La lucha de líderes kayambis, especialmente mujeres, de la talla de Dolores Cacuango y Tránsito Amaguaña, sin duda que han ayudado al fortalecimiento histórico de este pueblo, en referencia a temas como la tierra, la educación y la organización. En los últimos tiempos, los Kayambis han profundizado sus luchas para recuperar su memoria territorial y simbólica de pueblo superando las divisiones políticas impuestas. En 2004, Arturo Guasgua, dirigente de la Confederación de Comunidades de Pueblo Kayambi, nos hablaba de la delimitación del territorio como el principal objetivo de su organización. El territorio del Pueblo

6. Para tener una idea más clara del estado plurinacional puede consultarse Yañez del Pozo (2009).

7. Esta unidad (Ramón, 1987) de pueblos entre los ríos Guayllabamba por el sur y el Chota, por el norte es la que se toma como base para que en los tiempos actuales hablemos de la Nación Karanki dentro del Estado Plurinacional Ecuatoriano. 
Kayambi se encuentra distribuido en las provincias de Pichincha, Imbabura y Napo con las poblaciones de Chaco y Oyacachi. Actualmente se cuenta con la circunscripción territorial de Pueblo Kayambi y se tiene proyectada la declaración de patrimonio cultural de algunos valores tangibles e intangibles que están siendo definidos de acuerdo a un mapeo que realizamos (Entrevista del 19 de julio de 2004).

El actual dirigente de Pueblo Kakampi, José Andrango, nativo de la provincia de Imbabura, también enfatiza el proceso de unidad de las diferentes comunidades y organizaciones que integran pueblo Kayambi, en medio de los graves problemas que la gente enfrenta.

"Los principales problemas de nuestra gente son el desempleo, la falta de tierra propia y la pérdida de la identidad propia. A pesar de que cada vez hay más empresas especialmente florícolas, la gente sale a las ciudades, abandona su forma de vida campesina y sobre todo ya no quiere, en general, parecerse a los abuelos que eran los que tenían nuestra sabiduría que ahora queremos recuperar. Por eso quisiéramos que este trabajo sirviera para hacer materiales para las escuelas por ejemplo para rescatar todo lo que saben las parteras, que vienen de muchas de las comunidades $y$ organizaciones del Pueblo Kayampi" (Entrevista del 8 de mayo de 2009).

\section{EL SAS Y LA VIDA DIARIA}

En medio de estas condiciones tan adversas, sin embargo, nuestros pueblos en general, y muy especialmente el Pueblo Kayambi, a través de sus hombres y mujeres de sabiduría, ha conservado los rasgos fundamentales de lo que nosotros consideramos como la salud en la vida diaria, en su sentido más general. En primer lugar, el hombre andino siente que todo está relacionado con todo, sin que tenga que hacer separaciones entre material/ espiritual, concreto/abstracto, etc. Este principio de la relacionalidad es el principio que organiza todo. Inclusive lo que denominamos Dios es también relativo porque existe en relación a todo. Como una manera de poner ejemplos de esta relación generalizada, el sabio andino explica que hay una gran relación entre el macrocosmos y el microcosmos, entre el macrocosmos y los humanos, entre lo que ve que está arriba (jawa y janan), lo que está aquí (kay) y lo que está adentro (uku) y abajo (uray). El hombre sabio y la mujer sabia como la partera podrían sin mucha dificultad aceptar que siempre está presente este llamado principio de correspondencia. Esta correspondencia en el sentido vertical se completa cuando se mira que todo lo que existe no está solo sino que siempre aparece en pares. Este principio de complementariedad, Enrique Cachiguango lo explica bien cuando afirma:

"Desde el ser más grande hasta el más diminuto del universo son pares y complementarios. Macho y hembra, luz y oscuridad, caliente y frío. Lo masculino es negativo porque es caos, destrucción y desequilibrio. Lo femenino es positivo porque es armonía, equilibrio y construcción. ... Atsil Yaya (Gran Espíritu Pariversal masculino) y Atsil Mama (Gran Espíritu Periversal femenino) ... Kari Chaska 
(planeta Marte, masculino) y Warmi Chaska (planeta Venus, femenino) ... Inti (Sol, masculino) y Killa (Luna, femenina)... Samay (espíritu de luz y vida) y Supay (espiritu de oscuridad y muerte) ... montañas machos y montañas hembras ... piedras machos y piedras hembras ... tierra macho (árido y seco) y tierra hembra (fértil) ... plantas machos y plantas hembras, animales machos y animales hembras, hombres y mujeres, salud (femenino) y enfermedad (masculino)" (Cachiguango 2008: 20-21).

Este mundo andino que tiene correspondencias y que funciona a base de complementariedades en un conjunto muy interrelacionado no puede funcionar bien si no se da el principio de reciprocidad entre todos. Como los humanos no somos los únicos que existimos y menos aún somos el centro como hasta ahora hemos aprendido ${ }^{8}$, no podemos olvidar que somos como un conjunto de familias que nos comunicamos y nos necesitamos entre todos en una relación de diálogo y reciprocidad no de verticalidad o imposición. Enrique Cachiguango distingue cuatro familias que forman esta red de reciprocidad: la comunidad divina, la comunidad humana, la comunidad natural y la comunidad de los ancestros (2208: 21). Entre las cuatro comunidades hay una cadena de ofrendas que hacen posible la vida y que Josef Estermann (1998) llama la ética universal (o pariversal en el pensamiento de Cachiguango). Nada de bueno o de malo que se haga al interior de cada comunidad o entre ellas queda sin su recompensa para bien o para mal.

Ahora bien, y como ya hemos dicho, una de las complementariedades andinas es la relación entre la salud y la enfermedad. Para entender mejor como funciona este sistema, es necesario tener en cuenta algunas ideas centrales. En primer lugar, hay que entender que la Pachamama, madre que abarca todo lo que existe, abarca cuatro comunidades según el pensamiento de Enrique Chachiguango: la comunidad divina, poblada por divinidades masculinas y femeninas, las que, aunque a veces tengan nombres y apariencia cristiana, mantienen características propias poco analizadas; la comunidad humana que encierra a todos los seres humanos, los y las que recreamos y ayudamos a parir a la madre tierra para mantener la vida en el pariverso; la comunidad natural que está formada por los seres móviles e inmóviles, las plantas, los animales, la tierra, el agua, el aire, el fuego y sus respectivos ayas ${ }^{9}$, las montañas y sus apus ${ }^{10}$, las piedras y los demás seres naturales y los

\footnotetext{
8. Todo da para pensar que fue el pensamiento cristiano de origen judío el que habría expandido la idea del antropocentrismo, especialmente a partir del Renacimiento en el que se cuestionaba el hecho de haber pensado que Dios era el único centro (Teocentrismo luego entendido también como Cristocentrismo) para dar paso a la idea de homocentrismo.

9. Espíritus vitales de la naturaleza que viven en el agua, la tierra, el aire y el fuego

10. Espíritus vitales de las montañas.
} 
erenos $^{11}$; y la comunidad de los ancestros que nos protegen y que pueden ser o supay ${ }^{12}$ o samay ${ }^{13}$. La relación armoniosa entre las cuatro comunidades daría como resultado la vivencia del Sumak Kawsay o Buen Vivir.

El Sistema Andino de Salud (SAS), aparte de sus principios, cuenta también con sus propios terapeutas, entre los cuales están precisamente las parteras o wachachik mamakuna. En la investigación de Estermann (1998), los terapeutas, al igual que algunos sitios y tiempos, actúan como verdaderos puentes o chakanas, porque actúan de mediadores y se ubican entre los diferentes mundos y las diferentes complementariedades. No entramos a detallar la formación y las características de cada uno de los terapeutas, porque el objetivo central de este trabajo es la wachachikmama o partera, cuyos testimonios presentamos para entender mejor todo lo que es el SAS.

Para llegar a la conclusión de que el parto no es una enfermedad, tenemos que necesariamente hacer un breve recuento del sistema de patologías del SAS. Según la mayoría de los estudios (Estrella, Rodríguez, Fernández Juárez, Delgado, Polia, Yánez del Pozo), se puede hablar de tres tipos de enfermedades o desequilibrios: las enfermedades de la tierra o del campo, las enfermedades de Dios y las enfermedades de hombre. Las enfermedades de la tierra se producen cuando algunos elementos naturales como el aire, el frío o el calor "cogen" a una persona en sitios determinados. Así hablamos de "cogidos por el arco iris", "cogido por el frío", etc. Las enfermedades de Dios se producen generalmente por una alteración de las relaciones humanas y son de tales características que, cuando el sabio andino las descubre, las remite a la sabiduría de los "doctores del hospital". Las enfermedades de hombre o de calle son las causadas por una persona a otra por motivos como la envidia. Este tipo de enfermedades solamente las puede curar, cuando puede curarlas, un sabio andino realmente bueno. Ninguna de estas clasificaciones incluye al hecho del nacimiento de una persona porque ese solamente es un hecho fisiológico normal. Si se ha vuelto asunto de médicos y maternidades es simplemente por intereses económicos, por alteraciones en los hábitos alimenticios y, lo que es más grave, por controles políticos que pretenden regularizar todo. Lo anterior, claro está, no quiere decir que no haya necesidad de doctores y hospitales, especialmente en casos de emergencias, como ahora ocurre en Cayambe y lo veremos en su momento. El hombre y la mujer andinos sanos se caracterizan porque son felices y activos, trabajadores y participativos, recíprocos y generosos, celebrativos y espirituales, dice Cachiguango.

En cambio, si están enfermos son todo lo contrario: tristes y envidiosos, egoístas y solitarios, soberbios violentos, viciosos y materialistas. El complemento de la salud es la

11. Son espíritus de la música que viven en el agua, la tierra, el aire y el fuego.

12. Supay es el alma el pena, o el espíritu humano que no ha logrado llegar al chayshuk-pacha. (Cachiguango, 22).

13. Samay es el espíritu que ha logrado llegar al chayshuk-pacha (Cachiguango, 2008: 22). 
enfermedad. Lograr el punto intermedio, el equilibrio y la armonía es la base para tener salud, pero esta salud no se consigue para el humano sino también para las demás familias como las divinidades, la naturaleza y los ancestros... Todos tienen que tener salud, sumak kawsay o vida en plenitud para que el runa tenga también sumak kawsay. Cuando una de las familias (divina, humana, naturaleza y ancestros) llegan al desequilibrio o rompen la armonía es allí cuando aparece la enfermedad, cuando aparece la muerte. Generalmente la familia que siempre rompe la interconexión pariversal es la humana, por eso existen las diversas enfermedades y las diversas catástrofes naturales que la madre naturaleza provoca para llamar la atención de sus hijos e hijas para volver nuevamente a la armonía. De allí la enorme responsabilidad que tenemos para que la vida fluya en toda su fuerza. Nuestras vidas y de toda la Pacha-Mama dependen de nosotros mismos (Cachiguango, 2008: 39-41).

Este hombre y esta mujer andinos se unen en pareja y recrean la unidad familiar a partir de una vivencia propia de la sexualidad. Los cuerpos que se juntan, aunque sean entendidos de acuerdo a las enseñanzas de la escuela occidental, están posiblemente aún entendidos de acuerdo al pensamiento andino. Este pensamiento integra en el cuerpo humano varias dualidades, lo material y lo inmaterial, el sami. El sami o ánima se pierde cuando uno se enferma y el sinchi se pierde cuando uno se muere, según se puede comprobar en los rituales de curación (Yánez del Pozo, 2005: 45 y ss.). Este mismo cuerpo se compara con los varios mundos del pluriverso y que necesita estar equilibrado, especialmente en cuanto al equilibrio térmico, el balance frío-calor, tan importante para el tema que nos ocupa. Este cuerpo que engendra y disfruta de la relación sexual no es, sin embargo, un asunto solamente individual sino una vivencia colectiva y comunitaria que vive y recrea cultura y pensamiento. Esta vivencia, por supuesto, reclama constantemente una complementariedad entre los géneros, aunque cede también constantemente a la imposición patriarcal extendida en estas tierras desde la invasión europea ${ }^{14}$.

\section{LA FORMACIÓN Y SABIDURÍA DE LAS PARTERAS}

El Sistema Andino de Salud (SAS), que no se reduce únicamente a la sanación o la curación de las enfermedades, está muy vigente en el Pueblo Kayambi. Este sistema está estrechamente relacionado con los otros sistemas de vida de los runas. Los sistemas de producción, de alimentación, de socialización de los conocimientos y conductas, de la vivencia de la espiritualidad, de la administración de la justicia, del ejercicio dela autoridad están tan relacionados que son la base para la comprensión de lo que denominamos Sistema de Salud. Sin duda que una de las personas, de los terapeutas más importantes de todos los sistemas es la que en castellano llamamos partera. Es la que cumple las

14. Para una mejor comprensión de estos temas puede consultarse los libros Allikai. La salud y la enfermedad desde la perspectiva indígena (2005) y Abya-Yala Kuyarinakui (2007) de José Yánez del Pozo. 
funciones de acompañar a su pueblo no solamente en el evento del parto sino en todas las circunstancias de la vida no solamente de la mujer sino de todas las personas de la comunidad y del pueblo. Según el intelectual del pueblo otavalo de la nación karanki, Luis Enrique Cachiguango, "Katza",

"Unanchu-mama significa la madre de la tradición, la madre continuadora de la tradición. Es el término más apropiado en kichwa para designar a la partera porque su significado es integral que abarca los cuidados antes del parto, durante el parto, después del parto, las habilidades ginecológicas, obstétricas, pediátricas, parvularias, así como también el manejo básico de las medicinas herbolaria, energética (mal viento) y psicológica (espanto). También merece una mención especial su capacidad de consejería de la Unanchu-Mama en todo el proceso de gestación, nacimiento y crianza de los niños y niñas" (Cachiguango, 2008: 126).

Según esto, la historia que presentamos a continuación es solamente una pequeña muestra de la gran riqueza y sabiduría que tienen todas y cada una de las parteras kayambis. Rosa Cabrera vive en la Comunidad de Angla de la Parroquia San Pablo del Cantón Otavalo de la Provincia de Imbabura. Con ella fuimos juntos desde la entrada a la parroquia de González Suárez hasta su comunidad, rodeada de montañas, cercana al Tayta Imbabura. Nos recibe en el pequeño cuartito donde Mama Rosa atiende a sus pacientes. Cuando llegamos nos brinda agüita caliente y granos cocinados que nos satisfacen profundamente. Su esposo Vicente le acompaña y, junto a él, Mama Rosa, con las acotaciones puntuales de su esposo, empieza su profundo testimonio, en el que podemos encontrar tanto los aspectos socioeconómicos, políticos y culturales de contexto como los elementos específicos que definen su acción de sanadora y partera. Al comienzo, pues, su memoria nos lleva a los tiempos de las haciendas, con nombres de hacendados tan conocidos como Galo Plaza, presidente del Ecuador entre los años 1948 a 1952. Su personalidad es ambigua en cierto modo porque aparece como dueño de haciendas en varias provincias, admirado por algunos pero ciertamente cuestionado por muchos por su orientación pro estadounidense.

"Antes aquíhabía la Hacienda Zuleta, la hacienda Topo, ya nos organizamos nosotros y ahora nosotros estamos aqui; la hacienda Topo era de Galo Plaza. La comunidad de Angla en cambio era de nuestra propiedad. Galo Plazo había tenido deuda en el banco y nosotros no nos habíamos dado cuenta y habian estado haciendo un remate de la hacienda el Topo, ahí querían entrar otros, entonces no dejamos entrar y cogimos nosotros mismos, la hacienda Topo ya salió para la gente de aquí mismo, de esta zona", dice Mama Rosa.

En cuanto a su profesión de sanadora, y aún mucho antes de que Rosa se casara con Vicente, ella ya era muy conocedora de las artes de la curación y la partería.

"Yo comencé a trabajar como partera, como curandera antes de encontrarme con mi marido yo aprendí desde wawa con mi mamita. Mi mamita es partera, curandera, 
ella limpiaba el mal de calle, sabía ver en esperma, sabía ver si esta cogido la pisada, veía en donde han ido a poner prenda, sabía decir esto han puesto en Ambato, a donde San Gonzalo. Entonces mi mamita, ella misma iba a traer la pisada y el apunte que habían dejado, sabía ir llevado calientito la ropita y ya llegando a la casa hacía shunk ( ritual de llamado a la sombra escapada del paciente), cuando la paciente estaba bien grave nosotros teníamos que esperar en la puerta de la casa rezando tomando trago, puesto barra haciendo cruz se amarra en la puerta, mientras tanto el enfermo ya está remordiendo los dientes, pero no se enfría porque el corazón está vivo todavía, entonces mi mamita ya sabía estar llegando y el diablo ya está en la casa nos damos cuenta porque un huracancito chiquito entra, mientras tanto nosotros tenemos que estar rezando y tomando, entre unas tres o cuatro personas, llegando mi mamita hace shunku a esa ropita que ha venido trayendo, hace vestir y el enfermo hace revivir. Así mi mamita ha salvado a algunas personas. Yo, esa capacitación como mi mamita, yo no tengo, yo si curo mal de calle pero para comparar con mi mamita todavía me falta".

Aunque las dos eran buenas, y según la opinión de Vicente Cabrera, su esposa y su suegra no realizaban las mismas actividades ni tenían los mismos conocimientos.

"La mamá de ella sabía curar por otras comunidades y la mía por otro lado, los enfermos que les iba mal con los doctores les buscan. La mamá de ella había sabido ver en esperma, sabía ver en donde han trabajado al espíritu los envidiosos, estando viendo en esperma decía han ido a encender en Ambato, entonces tenemos que ir a traer, yendo a traer el espíritu sabía no más curar. Mi esposa ver en esperma eso es lo único que no sabe, del resto todo sabe", dice Vicente.

Rosa Cabrera valora en alto grado lo que aprendió de su mamá, aunque reconoce que su madre tal vez sabía más que ella misma, tal vez porque era la abuela, de la cual aprendió su mamá tanto secretos, la primera maestra de toda esta familia.

"Con mi mamita yo he andado desde chiquitica, también la abuelita de ella ha sido partera, dice que curaba, yo no conocí, pero mi mamita así me ha sabido conversar, me ha sabido contar me decía yo aprendí por mi abuelita. Yo era única hija, venían los pacientes con los wawas (bebés) con diarrea, para dar a luz y yo sabía ayudar haciendo agüitas y cuando ya caía el bebe ayudaba a coger. Yo ayudaba desde que tenía unos 9 o 10 años, sabía ya ver en el cuy, teníamos plantitas sembrado, yo sabía coger cual plantita es bueno para cada enfermedad, curaba con plantitas, sabía cual plantita es bueno, cual no es. Yo estaba siempre junto con mi mamita para aprender. Mi mamita me decía Rosa: 'aprenderás, no estarás llorando".

Como les pasa a muchas personas sabias, la pobreza extrema fue una de las características más comunes de su vida. Tal vez es esa misma pobreza, ese cúmulo de carencias lo que ha hecho que Rosa sea tan dedicada a sus pacientes y tan espiritual.

"Éramos bien pobrecitas, no teníamos que comer, tengo tres hermanos más, a veces 
teníamos para el almuerzo y para la merienda ya no teníamos. Con mi mamita sabíamos pedir a Diosito, salíamos a las 4 esquinas y sabíamos desvestir, lluchitos (desnuditos) pedíamos a Diosito para que nos de sabiduría, que nos de esta sabiduría cada vez más; pedíamos a Diosito cada media noche. Mi mamita también lloraba porque no teníamos que comer, en ese tiempo ya había escuela pero a mí no me puso, porque no teníamos con qué comprar ropa, con que comprar cualquier cosita; íbamos a misa y poníamos espermita a Diosito, a la Virgen María, íbamos a Otavalo, a San Pablo, para amanecer martes, viernes y domingo. Siempre salíamos al patio a media noche en punto, sacábamos la ropita y pedíamos a Dios, que nos de sabiduría para salir adelante, de ahí ya seguían no más llegando, más y más clientela y ahí ya teníamos para comprar faldita, para comer".

En la siguiente parte de su testimonio, Mama Rosa agradece a una mujer del pueblo Otavalo. Como sabemos, los dos pueblos, el pueblo Kayambi al cual pertenece Rosa y el pueblo Otavalo, los dos de la Nación Karanki, tienen realidades cercanas y aprendizajes similares, aunque a veces tengan también diferencias.

"Una otavalita sabía venir y ella decía verá Rosa aprenderá, y yo decía pero como voy hacer, entonces esa señora me decía tienes que pedir a Dios que te dé el poder, Taita Dios va a ayudar. Esa señora me dijo, Rosa levántate en luna llena y te irás a bañar en la quebrada de Parkawayku, porque ahí viene el agua de dos lados, en el medio tienes que bañar a las 12 en punto de la noche pidiendo a Dios y también tienes que pedir al lucero, a la niebla, a luna, a la Pacha Mama, al taita Imbabura para ver si así puedes aprender. Eso me he grabado en la cabeza y así hice en la luna que está amaneciendo pura. También me dijo sal al camino a las cuatro esquinas, pero te bañas en la acequia de Parkawayku, yo hasta ahora agradezco a esa señora, ella ya murió. Yo salía 12 en punto de la noche y me iba rezando, rezando, una maltita tenía para cargar agua esa me iba llevando, llegaba a ese puntito de la quebrada y bañaba, con un matecito y bañaba poniendo 12 matecitos en cada lado primero al lado izquierdo y 12 matecitos al lado derecho; ella me decía, coge ortiga, una rama de moras y una de chilca y límpiate vos misma o ruega a alguien que te limpie y bótate en el agua; todo eso hice, eso hice hasta tener los 17 años".

El conocimiento de las características y las propiedades de las plantas, aunque no nos fue revelado en su totalidad ${ }^{15}$ se ancla en las palabras de Rosa en la complementariedad fresco-cálido, eje central del SAS.

"Nos venían a llevar a todo lado, Zuleta, la Merced, así íbamos viendo las plantitas,

15. Rosa Cabrera ha sido muy tajante al afirmar que ni ésta ni ninguna investigación podía pretender llegar a conocer los más íntimos secretos de la sabiduría andina. Nosotros respetamos y alabamos esa firme convicción convencidos de que la sabiduría andina, manejada por el mismo pueblo, es quizá la única garantía de continuidad del pueblo y sus sabios. 
ahí amanecíamos y después limpiábamos con el cuy. Donde que estábamos curando íbamos a amanecer. Cogíamos unas plantitas para tomar, otras para hacer bañar, nos íbamos al monte y ahí cogíamos las plantitas y veíamos si esta plantita cura la enfermedad si es buena o no, si no era buena buscábamos otra. Así mismo los granos, veíamos para qué sirven los granos, veíamos este granito curó o hizo mal y así cambiábamos. Los granos son calientes y otros son frescos; así andábamos con mi mamita, veía como se limpia con el cuy, como se atiende el parto, como es de coger al wawa, qué ropita es para el bebe, qué ropita es para la paciente".

La organización política, concretamente la ECUARUNARI (Ecuador Runakunapak Rikcharimuy o el despertar del hombre andino del Ecuador) la principal organización de indígenas de habla kichwa del Ecuador), parte fundamental de la CONAIE (Confederación de Nacionalidades Indígenas del Ecuador), jugó un papel fundamental en la formación política e intelectual de Rosa. Aunque "le hacía falta la letra", como ella llama a la habilidad de leer y escribir, era su gran capacidad de grabarse las cosas la que hace de ella una verdadera maestra de su pueblo, de profunda tradición oral.

"De ahí, así, así entré a Ecuarunari, de ahí yo andaba, andaba, a mi hijo le decía tal día voy a salir y mi hijo me decía ándate no más calladito papá no ha de ver, calladito salía. Para el pasaje dejaba escondiendo los granitos en la zanja, para que él no se de cuenta, el rato de ir decía voy a ir por ahí me invitaron, ya sabía tener listo tostadito para cucabe (refrigerio), el rato que ya volvía mi hijo ya sabía estar esperando para que no pegue, así avancé a graduarme de partera, el rato que estuve graduando decía vos no sabes letra, no vas a poder trabajar sabía estar riéndose. Mi hijo decía cada que regresaba de curso ¿qué entendiste?, y mi hijo decía ¿qué piensas mamá?, yo venía grabadito todo en la cabeza, y decía todo lo que aprendo en los cursos con eso yo voy a trabajar. A veces decía yo sé todo, por qué no pongo a valorizar todo lo que yo sé, yo no soy de escuela, de gana me casé, en las comunidades no me hacen valer nada, me dicen esta no sabe nada es tonta, y decía ahora que hago. Entré en la Ecuarunari con la compañera Josefina Lema ella me dijo ya saben que están capacitadas, graben en la cabeza, piensen que tienen un libro en la cabeza y trabajen. Ya han sido capacitadas por aquí, por allá parece que lo que falta es la letra, y dije quien me va a apoyar a mí, pedí a Diosito para trabajar en el local".

Su capacitación aumentó más y más y su decisión de poner locales de atención en varios sitios le llevaron poco a poco a "aprender la letra".

"Una vez la compañera Magdalena Flores me había mandado un oficio, como yo no sé leer me dieron leyendo, me dijeron que me vaya entonces entré como promotora en CEMOPLAF [Centro Médico de Orientación y Planificación Familiar] ahí ya me capacité más. Ya tenía carné y me pusieron a que trabaje como promotora en todas las comunidades, andaba dando charlas de cómo ver y curar con el cuy, dije yo soy partera, se curar, como andaba en las comunidades seguía atendiendo los 
partos, así anduve con la organización trabajé así un año y me dieron un cuartito para que trabaje junto con la doctora. Mi primer local puse en Imantag, yo vivía tres años por ahí, las gentes venían acá a mi casa y me decían está lejos por qué no pone el local en Otavalo, ahí ya estoy con el local 6 años. Después dije letra mismo me falta, mi hijo había escuchado en radio Bajai para estudiar, ahí en radio y entré a estudiar, cogí un librito y dije parece que si voy a poder, 5 años ya estoy en la escuela, acabando quizá pueda ir al colegio".

Una vez que ha adquirido la formación necesaria, puede por fin ya estar segura de su proceso de diagnóstico y curación. Rosa sigue un orden muy pedagógico para enseñarnos cómo funciona la relación entre un diagnóstico muy minucioso y el consiguiente tratamiento.

"Si va a dar a luz, o si está enfermo primero hay que ver la temperatura por dentro de ahí podemos hacer medicina, no hay que hacer así no más. Para limpiar con el cuy o huevo hay que ver primero la temperatura del cuerpo por dentro, tenemos que ver cómo está la temperatura, como está en el corazón o riñón. Limpiando con el cuy bien debemos saber qué mismo tiene, viendo la médula, la sangre y después hacer remedio exacto, si no se sabe se puede morir, es peligroso, la temperatura es la que manda por dentro. Limpiando, en el cuy ya se ve todo, o se alcanza a ver tocando con la mano, vemos en el puso eso depende de las personas así ya sabemos que tiene $y$ que plantas necesita. En algunas personas aunque se toque no se sabe, ahí toca coger la orina para saber, se toca el corazón si es que está bien vivo se ve que planta es para eso. Mientras veo en el cuy, veo la médula, el hueso y de ahí veo que tiene, ya preparo para el corazón, para el riñón, el hígado una agüita preparo y le doy a tomar y después de una hora le pregunto cómo está, si ya tiene hambre, si se mejora ahí se ve cómo va cambiando el color, los huesitos ya mueve, si no mejora ahí se hace otra medicina, también se pone amarrando las hierbitas por el cuerpo o se ponemos machucando, poniendo en una sabanita envuelta".

Para el caso del parto, se sigue un proceso similar aunque la presencia de los familiares, y del esposo fundamentalmente, es algo que no siempre ocurre.

"Cuando esta de parto se está con la mujer, viendo la carita, tocando el pulso, hay que estar juntitos hasta 5 horas cuidando, habiendo mamá o esposo se amanece cuidando, sino amanece muriendo. Por eso no hay que dejar si no hay familiares que cuiden la partera tiene que cuidar, tiene que amanecer juntos. Algunos maridos no ayudan, la mayoría no se preocupan, están tomando, están por ahí, los familiares o los vecinos ayudan en el parto. Los esposos no dan mucha importancia. En el primer hijo si le quieren, cuando ya tiene dos tres ya no le quieren, hasta la mamá dice aunque wawa (niño) se muera, algunos así dice, yo ahí les estoy aconsejando".

El otro problema es el número de hijos. Rosa cree que no se debe tener muchos hijos y para eso ella misma aconseja a las mujeres como planificar. 
"Yo he dicho a los pacientes, para que no tengan muchos hijos haga planificar a la señora, vaya a donde el Doctor pero no sabe querer. Entonces yo le mando remeditos y cuidándose ya no llegan a tener, les digo tienes que cuidar hasta 6 meses, tú mismo. Yo les encadero (les compongo la cadera)para que no llegue a tener tan rápido y le dije tienes que estar 4 semanitas en la cama para que te sanes bien, de ahí tienes que caminar con wawito (niñito) en el patio hasta que cumplas tres meses, no te irás en carro, hasta cuando completes 6 meses no cogerás azadón".

Un tema siempre delicado es el de las relaciones sexuales. Ante la pregunta de si los esposos quieren enseguida o esperan, ella contesta:

"Yo me he dado cuenta, el esposo que quiere a la mujer como es debido, dicen yo cuido a la esposa cuando ha dado a luz, no tengo relaciones tan pronto para que mi mujercita sane bien y hasta viejita esté trabajando duro. Después que sale el bebe por fuera está sano pero por dentro la madre aún no sana, todavía está herido y sobre eso que tengan relaciones no es bueno, por eso hay que cuidarse para no estar enferma, para no sentirse adolorida la cabeza, los brazos, los pies, sanita bien y poder trabajar hasta los 90 años".

Si la mujer, y el marido y los hijos quieren tener una vida larga y sana tienen que cuidarse como lo hacían las personas de antes. Lo importante es que la misma partera está allí para acompañar a la mujer si esta lo necesita y ya no está sola.

"Yo he visto mujeres ancianitas ellas están bien, están sanitas pero ahora ya no es así mujeres de 35 años se sienten enfermas, están con dolor de cuello, ya no pueden caminar, los deditos de las manos ya están hinchados, los huesos están torciendo, para no tener ese problema antes de que cumpla 6 meses no tenga relación eso les digo yo a los esposos, si en verdad le quiere si cumplen. Hasta 8 semanas después de dar a luz debe estar sin comer carne la paciente, debe comer granitos, caldo de nabo, habas, morochito, todos los granitos, que tomen todos los días cháhuar mishqui (dulce que se extrae del penco). Que no le dé de comer fideo, papas de mercado, carne, porque la carne hace mal al hueso. Porque está curado con balanceado. Los borreguitos eso si es bueno, también las gallinas de campo. Cumpliendo 15 días le digo quieres ir a pasear solita o te acompaño. Nos vamos conmigo y le llevo los huesitos que después de dar a luz se rompen en el carro se van componiendo, otras veces nos vamos a pie hasta donde ella pueda, regresando le digo ahora si ya no levantarás, le pongo unas matas, unas ramitas en la cadera en los huesos y de ahí le pongo a encaderar".

El baño de la mujer no tiene ni la misma importancia ni la misma interpretación que para la gente de la ciudad. Tiene más bien que ver con el equilibrio térmico, que como ha hemos dicho es parte central del Sistema Andino de Salud (SAS).

"Después de 2 días se hace bañar con agüitas de hierbas, después de 8 días otra vez y a los 15 días otra vez, se baña con agüita de hierbas cocinando, no con agua fría. Depende, si el cuerpo está caliente se pone hierbitas frescas, Si el cuerpo está 
irritado se pone hierbita destemplada a cocinar. De ahí se baña cada 8 días. Es bueno bañarse con agüitas de hierbas después de dar a luz, pero bañar todo los días no es bueno, se enferma la sangre. Algunos no saben querer bañar ahí me voy hago cocinar agüitas y hago bañar".

Aunque las cosas y tradiciones antiguas son muy importantes, Rosa no desconoce que también necesita aprender cosas nuevas.

"Antes cortábamos el cordón con la flauta, hasta ahora mi esposo toca la flauta para bailar San Juan, esa flauta que ya no se usa se hacía una astillita y con eso cortábamos, teníamos ya quebradito, se sacaba una astillita pequeña, eso es filito $y$ con eso se cortaba. Las doctoras me dieron las tijeras, me daba miedo pero dije tengo que aprender, yo hago hervir agua con las tijeritas que me dieron, con la cinta".

Como también nos cuentan otras parteras, el tamaño según el cual se corta el cordón umbilical es muy importante y depende del sexo del niño tanto en su característica biológica como en su práctica de la sexualidad; como una prueba de la relación estrecha entre la madre y el hijo o hija, este cordón formará parte de vida de la persona a una edad en la que pueda darse cuenta plenamente de ello.

"En hombres se corta midiendo 4 dedos abiertos, para que el penecito sale normalito, si se corta más chiquito no es bueno sale chiquitito el pene y eso es malo cuando encuentra la mujer no alcanza y ella por eso busca amigo. Para mujercita se corta en tres dedos y ahí el parto es normal, así me enseñó mi mamita. Para cortar el ombligo la partera tiene que saber, según como mi mamita decía he hecho. El cordón después que ya se ha cortado se limpia con alcohol, rezo y pido a Diosito y nunca ha pasado nada, Yo les digo cuando caiga el ombligo no botarás guardarás y entregarás al hijo a los 20 años y entonces ahí el hijo ha de preguntar lo que quiera saber, así me enseñó mi mamita".

En cuanto a la placenta, Rosa solamente repite lo que la tradición de este pueblo aconseja. Es una tradición que, como es obvio, difiere mucho de la costumbre occidental.

"Cuando cae la placenta, se revisa que esté completa o si ha quedado un pedazo y ahí los familiares y el esposo están preocupados con un trapito para coger, se envuelve bien y antes de que se enfríe cerca de la candela cavamos un huequito hondo y ahí se entierra brevecito, porque si se enfría antes de enterrar la barriguita de la mamá se hincha, por eso nos preocupamos de enterrar brevecito antes de que se enfríe, se entierra a un metro de lejos del fogón antes de que se enfríe y así la barriguita de la madre no se hincha. Nunca hemos botado, eso es un secreto, nosotros hemos enterrado brevecito".

Otra cosa diferente es la envoltura del bebé apenas nace. Esta era una tradición bastante extendida entre la población ecuatoriana de cualquier lealtad étnica. Algunos estudios últimos, sin embargo, prácticamente lo prohíbe por considerar esta práctica dañina para el crecimiento del niño. Las parteras, sin embargo, con razón creemos, dan valor a esta 
forma de cuidar al bebé. Lo que más importa tal vez sea otra vez el equilibrio térmico de la nueva persona.

"Mas antes bañábamos con agua fría, hacíamos maytu (envuelto) con la chumpi [faja], siempre hacíamos maytu [envoltorio] hasta el año seis meses, así los bebecitos crecen duros, para trabajar también son dobles, trabajadores. Yo decía que les lleven al centro de salud para hacerles chequear y ahí sabian hablar, sabian decir para qué hacen esto, nunca hay que hacer esto, va a morir, va a enfermar no vale, les hablaban a la mayoría para que no hagan maytu, ele cada persona que va al centro de salud mandan hablando, ya la gente ya no quiere hacer maytu. Los wawas que crecen sin hacer maytu yo estoy viendo que están débiles, no pueden trabajar, no pueden cargar leña, no pueden trabajar con los azadones, están enfermos, ya no utilizan los trapitos que utilizábamos nosotros, desechables están poniendo por eso nuestra rabadillita así está enfermito. Porque hecho el maytu bien abrigadito, mano se pone recta, hueso sano no pasa nada de frío, wawas sin hacer maytu hacen de aire, cargado hay mismo orina por eso enferma, por eso la mayoría se enferma. Cuando nosotros hacíamos maytu no hemos visto que los wawitos se enfermen, pero ahora sí. Las señoras hasta un mes hacen maytu".

Este equilibrio, tan fundamental para todo, parte del mismo cuerpo. Dependerá de la frialdad o de la calidez de tal o cual parte del cuerpo para determinar el tratamiento respectivo.

"El cuerpo tiene sus partes frías y calientes, una sola temperatura hasta el pie es fácil dar cualquier medicina. La temperatura es una arriba y otra temperatura abajo, se necesita dar agüitas y granitos de acuerdo a la temperatura. Yo preparo solita los remedios que voy a dar y me equivoco cuando hay otras personas, por eso prefiero hacer sola. Hay que saber qué pasa en hígado o riñón, de acuerdo a eso se prepara y se da agüita de cualquier planta, no es bueno no más dar por dar, vaya a morirse. Después que les he dado la agüita, dejo pasar una horita y le pregunto cómo se siente, ya viendo como está, pongo a preparar otras hierbitas y la comida, a veces ya empiezan a mejorar y ya tienen hambre, ya van estando bien. Si no ha hecho bien, tengo que hacer otras agüitas, busco otras plantitas de acuerdo a lo que tiene y pongo unos granitos. Yo no duermo cuando tengo una paciente, siempre estoy preocupadísima. Nunca se ha muerto un niño o mujer, no, dando gracias a Dios".

\section{EL SOS, LA URGENCIA Y LA EMERGENCIA}

En una sociedad como la ecuatoriana, signada por la complejidad y la diversidad, la denominada modernidad avanza en todos los órdenes, arrasando con todo lo que parece oponerse a su incontenible carrera. Las sabidurías de los pueblos ancestrales y los propios pueblos con sus estilos de vida más saludables también son destruidos y aplastados. Por las condiciones propias del sistema mercantilista y excluyente en el que vivimos, y por 
la concepción que tiene occidente de lo que significa estar sano o enfermo, es obvio que a los gobiernos no les interesa orientar su acción a la verdadera promoción de la salud de los pueblos. Solamente así se comprende cómo la agricultura, por ejemplo, está prácticamente desatendida. En lugar de favorecer la pequeña producción que asegure una buena alimentación para los habitantes del país, se sigue facilitando las importaciones de algunos de los elementos básicos como el trigo. En lugar de plantear políticas de atención primaria que privilegien el cuidado de la salud en la vida diaria, mediante el acceso a los principales servicios como el agua y la electricidad o el alcantarillado y la vivienda, la educación según las propias culturas y lenguas y la participación política dentro de un verdadero estado plurinacional, se pretende equiparar la construcción sola de hospitales como demostración de buena salud.

De nada vale que el gobierno repita que tiene una deuda histórica con el agro (enlace sabatino oficial ${ }^{16}$ del sábado, 2 de marzo de 2013) si no se evita la masiva salida de campesinos a las grandes ciudades precisamente porque su trabajo agrícola no es suficientemente valorado ni apoyado. Aunque esto al fin solamente es un ejemplo de cómo funciona el sistema capitalista que parece haber diseñado para todo el mundo el apoyo único a ciertos polos del llamado desarrollo en torno a los cuales deben girar millones de personas desempleadas en pos de un mendrugo de pan. Solamente así también se explica la creciente inseguridad en las ciudades, cada vez más imposibilitadas de dar solución a tantos y tanto problemas no solamente económicos sino de propuestas de estilos de vida. Esto naturalmente no puede para nada conducirnos al denominado y manipulado concepto del Sumak Kwasay en el sentido de equilibrio pleno con las demás personas, los espíritus y la Pachamama.

En vista, entonces, de que la enfermedad está presente en todas las circunstancias de la vida y para todo tipo de persona, y de que los más pobres siempre están en alto riesgo de caer en urgencias o emergencias, según el riesgo que la vida corra, se hace obviamente necesaria la presencia de médicos y demás personal de salud, convenientemente formados. Aunque puede haber diferencias entre las facultades de medicina en cuanto a los contenidos y las metodologías de enseñanza y aprendizaje, veamos cómo funciona una facultad sin decir, por obvias razones, a cual específicamente nos referimos. Si un estudiante típico acaba el colegio a los 18 años y decide ingresar a esta facultad de medicina, se encontrará, de manera aproximada, con un proceso que se resume en las siguientes etapas:

- El Nivel Propedéutico, que dura un semestre y que trata de equilibrar los conocimientos aprendidos en los colegios, con materias básicas como Bioquímica,

16. El gobierno de la Revolución Ciudadana, durante tres horas semanales, los días sábados, en diferentes escenarios de la geografía nacional, ofrece, a través del Presidente de la República, un informe de las actividades realizadas durante la semana. Se aprovecha el espacio para responder acusaciones o aclarar situaciones en las que el gobierno cree sentirse afectado. 
Biología Celular, Física, Ofimática, Morfofunción (Histología, Embriología, Anatomía), Ingles y Antropología Medica. ${ }^{17}$

En las Ciencias Básicas, que incluyen los niveles 1ero, 2do y 3ero, se estudia Morfofunciòn I (Sistema Respiratorio, Sistema Digestivo, Sistema Muscular), Optativas (fotografía) y las Prácticas en Hospitales (signos vitales).

En las Ciencias Clínicas, corazón mismo de la formación de los médicos, y que incluyen los niveles 4to, 5to, 6to, $7 \mathrm{mo}$ y 8 vo se estudian materias como Morfofunciòn II (Sistema Nervioso, Sistema Hematopoyético, Órganos de los sentidos, Sistema Cardio Circulatorio, Pediatría, Ginecología, Emergencia, Psiquiatría, Medicina Alternativa, Practicas de externado (primeras Guardias

17. Aunque todas las facultades de medicina incluyen en su pensum una materia llamada Antropología Médica, no todos los profesores la entienden de la misma forma. Muchos la entienden como un recorrido por la historia de la medicina en general y en el país. Otros la entienden como reflexiones generales sobre los museos de medicina desde los tiempos coloniales hasta la actualidad. Otros, por fin, gustan de remitirse a algunas prácticas de salud provenientes de los llamados chamanes. De lo que conocemos, hay una facultad de ciencias de la salud en una universidad de Quito que ya por varios años ha tratado de orientar la reflexión por otro lado. Se parte de la comprensión de que todo principio y práctica de salud obedecen a un pensamiento profundo, a una comprensión general de lo que se entiende no solamente por salud y enfermedad sino también sobre la vida y la muerte, el bien y el mal, el hombre y la mujer. Se toma distancia así, y de manera muy radical, del Sistema Occidental de Salud, que es el que se enseña y se practica en la sociedad nacional, heredera de un pensamiento profundo de orígenes claramente europeos. El Sistema Andino de Salud, así, ya no es tomado como un conjunto más o menos vistoso y anecdótico sino como la respuesta o el conjunto de respuestas que los pueblos originarios de cualquier parte del mundo han dado a sus necesidades generales de su vida. Entran aquí las relaciones con el propio cuerpo y los demás cuerpos y personas, las relaciones con los espíritus y los ancestros y, muy especialmente, la relación con la Pachamama. Este tipo de equilibrio es considerado como el disfrute ideal de la salud, es un sistema de salud que sirve para la vida toda, en toda su complejidad. En este contexto, se analizan tanto los tipos de patologías como sus respectivos agentes, tiempos y elementos de sanación, la relación que hay con las condiciones económicas y políticas de los pueblos concretos, así como la necesidad de ampliar estas ideas a todas las facultades formadoras de médicos y más personal de salud. Si se pone en relación, sin embargo, la formación central del estudiante con esta clase o similares, el desbalance es obvio. A lo mejor se consigue algo más de sensibilidad en algunos de los estudiantes, en el sentido de una mayor apertura a otras culturas y otros pensamientos tan lejanos a la vez que tan cercanos. Esto obviamente no va a incidir de mayor manera en la práctica profesional no solamente por culpa de los mismos médicos y odontólogos sino por las necesidades del mercado y por la imposición de los ministerios de salud a los que definitivamente no les importa mucho ni la situación real de nuestros pueblos propios ni la situación real de la salud de todos los habitantes del país, en tanto que esta propuesta está planteada para todos. 
Maternidad Isidro Ayora, Hospital del Sur, Patronato San José, Psiquiátrico Sagrado Corazón de Jesús).

- Cuando llega el Internado se procede a las Prácticas en Hospitales Públicos en las diferentes áreas (Ginecología, Pediatría, Emergencia, Cirugía, Medicina Interna, Traumatología, Urología, Cirugía Vascular).

En la etapa llamada Pre rural, los estudiantes deben pasar dos meses tanto en Nuevo Rocafuerte (Amazonía fronteriza con el Perú) y en Zumbahua, zona de páramo, de la provincia del Cotopaxi.

- Para la graduación se debe aprobar exigentes exámenes que demuestren el manejo adecuado de los conceptos centrales de la profesión, adquiridos tanto en las aulas como en las prácticas.

- El año de Medicatura Rural es el tiempo precioso del nuevo profesional. Si antes actuó siempre bajo el control y la orientación de alguien, será este tiempo la oportunidad para demostrarse a sí mismo cuánto puede realizar un trabajo tan delicado. Luego del estrés del sorteo que supone abandonar la ciudad y la familia para ir a trabajar como profesional en lugares generalmente rurales alejados, el trabajo presenta las siguientes oportunidades para completar la formación: las habilidades para diagnosticar de acuerdo a lo aprendido y a las condiciones propias de la gente y la capacidad de resolución de problemas del más diverso tipo. Entre las responsabilidades mayores del médico rural, sin duda, destacan tanto la necesidad de coordinar los esfuerzos médicos del equipo del cual uno ya es parte con los dirigentes de la comunidad, como las exigencias del Ministerio de Salud el que, a pesar de la buena voluntad que podría haber, tiende a enredarse en exigencias burocráticas. Algo que se debe destacar como un proceso único es tal vez la Campaña Manuela Espejo de la Vicepresidencia de la Republica, para ayudar a las personas con discapacidad. De todas formas, todo depende tanto del lugar al que uno llegue como del propio profesional para estar dispuesto a aprovechar todas las potencialidades en el sentido de la colaboración, de la generosidad y la gratitud hacia el servicio que uno hace. Esta etapa es tan importante porque define la carrera profesional no solamente en el sentido de la especialización sino sobre todo en la disponibilidad hacia un servicio muy difícil y agotador.

Si después de atravesar por cada una de las etapas anteriores, el joven profesional debe trabajar en un hospital público del Ecuador, como es el caso del Hospital Maldonado Mejía, en la cabecera cantonal del territorio del Pueblo Kayambi, lo siguiente es lo que en general encontrará: este hospital tiene alrededor de 30 años y fue establecido como un centro de segundo nivel para atender a la población del cantón Cayambe, aunque en la realidad la atención rebasa el cantón para extenderse a todo el territorio del antiguo pueblo kayambi. Tanto para lo que se podría llamar urgencias como las denominadas emergencias, cuenta con los siguientes servicios: urgencias, pediatría, ginecología, 
cirugía general, traumatología, medicina interna y dermatología, a los cuales se debe añadir un servicio específico de emergencias. La demanda mayor va por el lado de la ginecología y la pediatría por la cantidad de partos que, por desgracia, ya son casos de urgencia ${ }^{18}$. Si consideramos la población general atendida, al hospital acude gente que generalmente se auto considera mestiza ${ }^{19}$, aunque también se atiende a las personas definidas como indígenas ${ }^{20}$. La población indígena atendida viene fundamentalmente de Cangahua, Guachalá, Otón, Juan Montalvo, Tabacundo y González Suárez ${ }^{21}$.

Un hospital como este, y pese a las graves limitaciones ${ }^{22}$, da la oportunidad a los profesionales de contribuir a la curación de la gran mayoría de pacientes hospitalizados tanto por el esfuerzo del personal de salud que sacrifica horas de su tiempo y presupuesto de sus ingresos como por la capacidad profesional adquirida a lo largo de los años, no solamente aquí sino en establecimientos tal vez de peores condiciones. Junto a estos importantes logros, aún le queda al hospital una serie de desafíos, entre los cuales podríamos enumerar los siguientes: un toma de conciencia por parte de las autoridades en cuanto al trato debido a los profesionales más jóvenes o en proceso de formación; un cambio radical en cuanto a que no es la cantidad de pacientes atendidos para mantener

18. Aunque no tenemos una estadística precisa, estamos en capacidad de afirmar que cada vez más mujeres se ven obligadas a dar a luz en el hospital sea porque temen una complicación como por la exigencia del Ministerio de Salud en cuanto a los controles mensuales a cambio de un bono del gobierno. Como se puede deducir, esto sin duda que va en detrimento de la labor de siglos de las parteras aparte de recargar el trabajo del personal hospitalario.

19. El término mestizo es muy ambiguo. Aunque en muchos de nuestros países se lo toma para referirse a la persona que tiene dos orígenes étnicos, uno europeo y otro indígena, en realidad esto solamente tiene que ver con la mezcla biológica, algo bastante obvio. En cuanto al pensamiento profundo y a sus estilos de vida, el llamado mestizo actúa o pretende actuar mayoritariamente en referencia a los cánones europeos, en oposición, por tanto a todo lo indígena fundamental.

20. Esta autoadscripción es muy importante para nuestro estudio por cuanto, aún en medio de un ambiente por siglos opuesto a lo indígena, hay cada vez más gente que opta por esta identidad no solamente para ciertos casos sino para todos los aspectos de la vida social y política. Los porcentajes de las llamadas minorías, en este sentido, deben tomárse solo como referentes censales ya que lo que está en juego es nada menos que estilos de pensamiento y vida más naturales y por tanto mucho más amigables con la Madre Naturaleza y los espíritus, como ya hemos dicho.

21. Posiblemente esto se deba a una antigua relación con la dinámica de la ciudad de Cayambe que supera ampliamente los límites cantonales para seguir cubriendo los amplios territorios del Pueblos Kayambi.

22. Las más graves limitaciones son la falta de personal, la dificultad de contar con exámenes complementarios y el poco abastecimiento de medicinas, cosas que no ocurren en otros centros similares pero con mayor cantidad de apoyos internacionales. 
tal o cual servicio sino la calidad y especialmente la calidez entendida como empatía que se debe sentir con el dolor del paciente.

\section{6. ¿SERA POSIBLE UN SISTEMA COMPLEMENTARIO DE SALUD EN UN VERDADERO ESTADO PLURINACIONAL?}

Por lo escrito hasta ahora, parece aún lejano el día en que se dé la posibilidad real de que los dos sistemas de salud que aparecen esbozados en este artículo sean capaces de armonizar intencionalmente sus teorías y sus prácticas. Como hemos dicho, cada uno de los sistemas procede de una matriz lógica e ideológica diferente, es decir de concepciones distintas sobre lo que se entiende por salud y por enfermedad y las maneras de recuperar la salud perdida. En una sociedad ideal lo normal debería ser estar relativamente sanos, por el tipo de alimentación y por el tipo de relaciones con la gente, la Madre Naturaleza y los espíritus. Sin embargo, como ya hemos repetido, ahora lo normal parece ser estar enfermos y la emergencia parece también convertirse poco a poco en parte fundamental de la vida diaria. Se da, según nuestro punto de vista, una especie de esquizofrenia que supone una alteración mental que distorsiona la realidad para hacer creer que los deseos, en este caso, de estar sanos, se solucionan con más asistencia médica y no con la vida más simple y armoniosa que, a pesar de todo, se sigue proponiendo desde nuestros propios pueblos, tachados de pobres, pero realmente dueños de una visión más integral de las cosas. Creemos que esta es precisamente la invitación que viene desde el Sistema Andino de Salud y está dirigida a todos, incluidos los profesionales del Sistema Occidental de Salud y las autoridades que lo administran, una invitación al diálogo entre dos sistemas que responden a dos lógicas diferentes, dos pensamientos profundos, dos filosofías dentro del mismo estado. 


\section{REFERENCIAS BIBLIOGRÁFICAS}

Acosta, Alberto y Martínez, Esperanza (2009) Plurinacionalidad. Democracia en la diversidad, Quito: Editorial Abya - Yala.

Adams, Walter Randolph and Hawkins John P. (2007) Health Care In Maya Guatemala. Confronting medical pluralism in a Developing Country. Norman: University of Oklahoma Press.

Breilh Paz y Miño, Jaime y Tillería Muñoz, Ilonka (2009) Aceleración Global y Despojo en Ecuador. El retroceso del derecho a la salud en la era neoliberal. Quito: Universidad Andina Simón Bolívar - Abya-Yala.

Cachiguango "Katsa", Luis Enrique (2002) Pakarina. El ritual Andino del nacimiento y crianza de niños y niñas en Cotacachi. Cruz Roja Ecuatoriana, UNORCAC, Municipio de Cotacachi. Cotacachi: s/f.

Cachiguango "Katsa", Luis Enrique (sin fecha) "Informe de Talleres realizados en el Cantón Cayambe con adolescentes de Colegios". Cayambe: CCC, s/f. (mimeo).

Delgado, Hugo (2001) “"Pensamiento” y “Sentimiento” en la comprensión del cuerpo humano", Cuadernos de Medicina Tradicional, 4.

De Marco, Danilo (Comp.) La sabiduría y el arte de las Parteras, sapienza e arte. Wachachik mamakunapak sumak yachaykuna. Circolo culturale Menocchio, s/f.

Estermann, Josef (1998) Filosofía Andina. Estudio intercultural de la sabiduría autóctona andina. Quito: Editorial Abya - Yala.

Estrella, Eduardo (1977) Medicina Aborigen. Quito: Editorial Época.

Fernández Juárez, Gerardo (1999) Médicos y yatiris. Salud e Interculturalidad en el Altiplano Aymara. La Paz: Cuadernos de Investigación CIPCA.

Flores Andi, Dorian, Paza Guanolema, Manuel y Yánez del Pozo, José Ñukanchik kawsayta kutin kawsankapak. Las naciones y pueblos indígenas reconstituyendo nuestra memoria colectiva hacia la aplicación del concepto integral de salud. http://new.paho.org/ hq/index2.php?option=com content $\&$ do $\mathrm{pdf}=1 \& \mathrm{id}=1682$

Kimlicka, Will (2012) "Estados multiculturales y ciudadanos interculturales" V Congreso Latinoamericano de Educación Intercultural Bilingüe. Lima.

Ministerio de Salud Pública del Ecuador (2008) Guía Técnica para la Atención del Parto Culturalmente Adecuado. Quito: CONASA.

Pacari, Nina y Vega, Luz Marina (2009) Marco Conceptual de los Objetivos de Desarrollo del Milenio desde la Perspectiva de los Pueblos Indígenas. Quito: OPS - OMS.

Polia Meconi, Mario (1998) Las lagunas de los encantos. Medicina tradicional andina del Perú Septentrional. Piura: Central Peruana de Servicios - CEPESER.

Ramón V, Galo (1987) La resistencia Andina. Cayambe 1500 - 1800. Quito: Editorial CAAP.

Rojas Almeida, Rocío (2003) Crecer sanitos. Estrategias, metodologías e instrumentos para investigar y comprender la salud de los niños indígenas. Washington, DC.: OPS. 
Rodríguez, Germán (1998) La sabiduría del Kóndor. Un ensayo sobre la validez del saber andino. Quito: Abya-Yala, Dineib, Proyecto EBI-GTZ.

Tipanluisa, Geovann (2008) "Mi hijo no fue prematuro y murió". Quito: El Comercio, 9 de noviembre de 2008, p. 29.

Verdugo, Juan Carlos (2002) Hacia un primer nivel de atención en salud incluyente. Guatemala: Medicus mundi.

Yánez del Pozo, José (1986) Yo Declaro con Franqueza. Cashnami Causashcanchic. Memoria Oral de Pesillo - Cayambe. Quito: Editorial Abya-Yala.

Yánez del Pozo, José (2002) Yanantin. La filosofía dialógica e intercultural del Manuscrito de Huarochiri. Quito: Editorial Abya-Yala.

Yánez del Pozo, José (2003) Runa Yachay. Socialización infantil y lógica de subsistencia en los pueblos indígenas del Ecuador. Quito: Editorial Abya-Yala.

Yánez del Pozo, José (2005a) Allikay. La Salud y la Enfermedad desde la Perspectiva Indígena. Quito: Editorial Abya-Yala.

Yánez del Pozo, José (2005b) Mi nombre ha de vivir y yo me he de ir a mi destino. Género, producción y aprendizaje intercultural en los pueblos Andinos. Quito: Editorial Abya-Yala. Yánez del Pozo, José (2009) "Pueblos y culturas vernáculas: cambios y su presencia actual. Nacionalidades y pueblos, ayer y hoy”. En Ángel Montes del Castillo (ed.) Ecuador Contemporáneo. Murcia: Universidad de Murcia, pp. 223-240.

Yánez del Pozo, José (sin fecha) "La lógica de la relacionalidad en el mundo Andino", http://alainnet.org/active/26655\&lang=es. 